\title{
Mentorship in Surgical Training: Current Status and A Needs Assessment for Future Mentoring Programs in Surgery
}

\author{
P. Sinclair · J. E. F. Fitzgerald · S. T. Hornby • \\ J. Shalhoub
}

Published online: 15 October 2014

(C) Société Internationale de Chirurgie 2014

\begin{abstract}
Aims Mentoring has been used extensively in the business world to enhance performance and maximise potential. Despite this, there is currently a paucity of literature describing mentoring for surgical trainees. This study examined the current extent of mentoring and investigated future needs to support this.

Methods An electronic, 47-item, self-administered questionnaire survey was distributed via national and regional surgical mailing lists and websites through the Association of Surgeons in Training and Specialty Associations in the UK and Republic of Ireland.

Results Overall, 565 fully completed responses were received from trainees in all specialties, grades and training regions. A total of $48.7 \%$ of respondents reported that they have a surgical mentor, with no significant gender difference $(p=0.65$ ). Of respondents, $52.5 \%$ considered their educational supervisor and $45.5 \%$ their current consultant as mentors. Modal duration of mentoring relationships was 1-2 years (24.4\%). A total of $90.2 \%$ of mentors were in the same specialty, $60.7 \%$ in the same hospital, and $88.7 \%$ in the same training region. Mentors covered clinical and professional matters $(99.3 \%$ ) versus pastoral and non-clinical matters $(41.1 \%)$. Mentoring was commonly face to face or via email and not documented $(64.7 \%)$. Of the $51.3 \%$ without a mentor, $89.7 \%$ would like a clinical mentor and $51.0 \%$ a pastoral mentor $(p<0.001)$. Priority mentoring areas included career progression $(94.9 \%)$, research $(75.2 \%)$, clinical skills $(66.9 \%)$ and clinical confidence $(58.4 \%)$. A total of $94.3 \%$ would be willing to act as a peer mentor. Only $8.7 \%$ had received mentoring training; $83 \%$ wish to undertake this.

Conclusions Less than half of surgical trainees identified a mentor. The majority want mentoring on professional topics during their training and would additionally be willing to peer-mentor colleagues, although few have received training for this. Despite an identified need, there is currently no structure for organising this and little national provision for mentoring.
\end{abstract}

Previous Conference Presentation The preliminary results of this survey were delivered as an oral presentation at the Association of Surgeons of Great Briton and Ireland conference last year and published in abstract form: Sinclair P, Fitzgerald JEF, Hornby ST, Shalhoub J. Coaching and mentoring in surgical training: overrated or underdeveloped? Results of a national pan-speciality trainee survey. British Journal of Surgery 2013; 100 (S7): 67.

On behalf of the Council of the Association of Surgeons in Training (http://www.asit.org).

Electronic supplementary material The online version of this article (doi:10.1007/s00268-014-2774-x) contains supplementary material, which is available to authorized users.
P. Sinclair $(\bowtie) \cdot$ J. E. F. Fitzgerald $(\bowtie) \cdot$ S. T. Hornby ·

J. Shalhoub

Association of Surgeons in Training, 35-43 Lincoln's Inn Fields,

London WC2A 3PE, UK

e-mail: piriyah.s@gmail.com

URL: https://twitter.com/ASiTofficial

J. E. F. Fitzgerald

e-mail: edwardfitzgerald@doctors.org.uk

URL: https://twitter.com/ASiTofficial 


\section{Introduction}

The term mentor emerged in Greek mythology when Odysseus chose a 'mentor' to watch over his son [1]. According to Chung, a mentor is "an active partner in an on-going relationship who helps a learner to maximize his or her potential and reach personal, professional goals ... [resulting in] ... a personal developmental relationship in which a person with greater knowledge or experience helps another with less" [1].

Mentoring subsequently appeared more widely in academic literature from the late 1970s, initially in business to identify and enhance employee performance [2]. Considerable evidence has now emerged from fields outside of medicine, indicating that mentoring can aid career progression and improve job satisfaction [3-5]. Mentorship within medicine has developed more recently, with growing acceptance of its importance in professional and personal development [6]. Numerous initiatives to develop mentoring programs have now been described, largely within medical schools and academic medical programs [7, 8].

Within surgery itself, mentoring is supported by a position statement on the subject by the Royal College of Surgeons of England [9], which highlights the potential benefits of these positive interactions, including career success, job satisfaction and improved working relationships with colleagues and patients. The American College of Surgeons also recognizes the importance of mentoring in surgery [10], with several Presidential Addresses of both the College and Specialty Associations focussing on this topic [1, 10, 11]. Recently, systematic reviews have addressed the utility of mentoring in the attainment of technical endpoints in surgery [12], as well as the opportunities and barriers to mentoring schemes in this context $[13,14]$. Trainees have also cited formal mentoring by seniors as a key support strategy helping them navigate the rigors of surgical training. The wider role and benefits mentorship may play in the lengthy and complex course of surgical training remain unclear. This lack of clarity may account for the current failure to trial mentoring on a larger scale within postgraduate surgical training [15].

Although numerous studies have considered the potential role for mentoring in surgery [16, 17], there is currently little published data addressing the needs and frameworks for this [18]. Within the UK and Republic of Ireland, there are no dedicated national mentoring programmes for surgical trainees and no national formalised training opportunities for those wishing to act as mentors. Such mentoring has a valuable role to play in enabling trainees to achieve their maximum potential, whilst developing leadership and interpersonal skills. Effectively mentored trainees may also go on to become effective mentors.
This national study examined the current state of mentoring in surgical training, together with a needs assessment for this.

\section{Methods}

\section{Definitions}

For the purposes of this study, mentoring in surgery was defined as "a relationship between two people in which trust and respect enables problems and difficulties to be discussed in an open and supportive environment" [19].

\section{Participants and setting}

In the UK, following completion of an undergraduate medical degree, all graduates enter a 2-year generic postgraduate training programme (the 'Foundation Programme'). Subsequently, doctors wishing to pursue a career in surgical specialities apply through a UK-wide national competitive selection process into a 'Core Training' programme lasting 2 years. Core Training may be generic or themed around a particular surgical speciality, and is followed by competitive application for a 'Speciality Training' (ST) programme. Specialty Trainees (Registrargrade doctors) enter schemes that last up to 6 years and provide dedicated training in one of the ten defined surgical specialities (cardiothoracic, general, maxillofacial, neurosurgery, orthopaedics and trauma, otolaryngology, paediatric, plastic, urology and vascular surgery). During this period, trainees will rotate between hospitals and supervising consultants, usually at 6-monthly intervals.

Trainees are allocated a named educational supervisor during each of these training periods, who may be the same as their supervising consultant surgeon. Educational supervisors are responsible for supporting and monitoring trainees' clinical and educational progress, and ensuring the trainee receives appropriate career guidance and planning. This is not a formal mentoring role, and no mentoring training is provided for the educational supervisor. However, the nature of this means that it may develop into an ongoing mentoring relationship, depending on the participants.

At the end of ST, upon successful demonstration of the required competencies, including passing an exit examination set by the Surgical Royal Colleges, a surgeon receives a Certificate of Completion of Training (CCT). More detail regarding the relevant structure and pathways through surgical training in the UK has previously been described elsewhere [20]. Across the UK, as of 2014, there were 1,359 Core Trainees and 4,335 Specialty Trainees registered in surgical training programmes [21]. 
This study was undertaken by the Association of Surgeons in Training (ASiT), a professional body and independent educational charity working to promote excellence in surgical training across the UK and Republic of Ireland.

\section{Questionnaire design}

A novel, 47-item, self-administered online questionnaire survey was developed exploring demographics, and current status of and future needs for mentoring within surgery. This consisted of free-text, binomial and 5-point Likert scale responses. The questionnaire included the aforementioned definition of mentoring used in this study so that survey participants were able to respond from a standardised viewpoint of what mentoring was considered to represent. Question logic was utilised to distinguish between respondents who had a current mentor and those without. The questionnaire was designed with reference to previously published guidelines on questionnaire research [2224]. The survey tool was peer-reviewed by experienced trainers and piloted by over 20 surgical trainees with a spread of seniority and specialty. Content validity was ensured by peer-review and piloting process. Face validity was ensured through careful sequential design using the professional online survey interface and checked during peer review. Test-retest and inter-observer reliability were not appropriate to establish with this study design. Given the range of different constructs measured, internal consistency calculations were not performed. The feedback received was used to iteratively refine the question items. All question items were compulsory and, given the anonymous nature of this survey, no additional individually identifiable information was collected (e.g. email address). Non-responders could therefore not be identified for follow-up. A complete copy of the questionnaire is included as supplemental information.

\section{Questionnaire distribution}

Doctors in surgical training in the UK and Republic of Ireland were invited to participate in this non-mandatory survey through surgical mailing lists and websites by ASiT, trainee surgical specialty associations and local mailing lists. Responses were collected through the SurveyMonkey web-survey portal (SurveyMonkey.com, LLC, Palo Alto, CA, USA). Answer randomisation was enabled where appropriate in order to minimise order bias, with IP address blocking to limit entries to one per invitation. The online questionnaire survey was open from August to December 2012 and re-publicised at regular intervals in order to maximise the response rate. No incentives were offered for participation.
The authors gave due consideration to the ethical dimensions of this non-mandatory questionnaire survey, and no concerns were identified. Completion of the questionnaire was taken as consent to participate.

Data analysis

Only fully completed questionnaires were included in the subsequent analysis. Analysis of results was undertaken using the Statistical Package for the Social Sciences, SPSS version 17.0 (SPSS Inc. Chicago, IL, USA). P values were calculated using Fishers' exact test. Free-text responses were independently categorized by theme into groups for analysis by two of the authors, with differences resolved by discussion. Survey sample size calculations were based on standard published formulae [25].

\section{Results}

Respondent demographics

Of 618 responses submitted, 565 were fully completed and entered into the analysis. This was sufficient to obtain a $\pm 3.91 \%$ margin of error at a $95 \%$ confidence level. The demographics of respondents are summarised in Table 1. Overall, $63.5 \%$ were male and the mean age was 32.2 years (range 23-48). Responses were received from trainees in all ten surgical specialties, all training regions and all grades. Overall, $5.1 \%$ of responses were from foundation trainees, $21.1 \%$ from core trainees, $59.9 \%$ from specialty trainees (registrars) and the remainder comprised other training grades (e.g. research or clinical fellowship post holders).

\section{Current mentoring relationships}

Table 1 summarises the varying proportions of respondents able to identify a current mentor. Overall, $48.7 \%$ of respondents reported that they currently had such a mentoring relationship. There was no significant gender difference $(p=0.65)$ in responses. Senior trainees more frequently self-identified a mentor. Academic trainees were less likely to have a surgical mentor (36 vs. $51 \%$; $p=0.03)$. There was no difference identified between fulltime and less than full-time trainees $(p=0.69)$. Regional variation in the proportion of trainees with self-identified mentors ranged from 34 to $68 \%$.

Of the trainees with a mentor, $60.4 \%$ had more than one mentor, and $30.3 \%$ of these were reported as undertaking different aspects of mentoring (e.g. clinical and pastoral). A total of $52.5 \%$ considered their educational supervisor and $45.5 \%$ their current consultant as mentors (Fig. 1a). 
Table 1 Demographics of respondents and current mentoring status

\begin{tabular}{|c|c|c|c|}
\hline \multirow[t]{2}{*}{ Characteristic } & \multicolumn{3}{|c|}{$\begin{array}{l}\text { Within surgery, do you currently } \\
\text { have someone you would consider } \\
\text { to be a mentor? }\end{array}$} \\
\hline & $\begin{array}{l}\text { Yes, } n(\% \text { of } \\
\text { row total })\end{array}$ & $\begin{array}{l}\text { No, } n(\% \text { of } \\
\text { row total })\end{array}$ & Total \\
\hline \multicolumn{4}{|l|}{ Gender } \\
\hline Male & $170(47.4)$ & $189(52.6)$ & 359 \\
\hline Female & $105(51.0)$ & $101(49.0)$ & 206 \\
\hline \multicolumn{4}{|l|}{ Country of qualification } \\
\hline UK & $220(51.0)$ & $211(49.0)$ & 431 \\
\hline Republic of Ireland & $21(44.7)$ & $26(55.3)$ & 47 \\
\hline Other (please specify) & $34(39.1)$ & $53(60.9)$ & 87 \\
\hline \multicolumn{4}{|l|}{ Less than full-time trainee? } \\
\hline Yes & $13(41.9)$ & $18(58.1)$ & 31 \\
\hline No & $262(49.1)$ & $272(50.9)$ & 534 \\
\hline \multicolumn{4}{|l|}{ Academic trainee? } \\
\hline Yes & $34(64.2)$ & $19(35.8)$ & 53 \\
\hline No & $241(47.1)$ & $271(52.9)$ & 512 \\
\hline \multicolumn{4}{|l|}{ Hospital type } \\
\hline District hospital & $96(44.2)$ & $121(55.8)$ & 217 \\
\hline $\begin{array}{l}\text { Specialist centre (specialty or disease } \\
\text { based) }\end{array}$ & $30(62.5)$ & $18(37.5)$ & 48 \\
\hline Teaching hospital & $149(49.7)$ & $151(50.3)$ & 300 \\
\hline \multicolumn{4}{|l|}{ Current surgical speciality } \\
\hline Cardiothoracic surgery & $12(66.7)$ & $6(33.3)$ & 18 \\
\hline $\begin{array}{l}\text { General surgery (excluding vascular } \\
\text { surgery) }\end{array}$ & $141(49.6)$ & $143(50.4)$ & 284 \\
\hline Neurosurgery & $3(16.7)$ & $15(83.3)$ & 18 \\
\hline Not currently in post (e.g. maternity) & $4(17.4)$ & $19(82.6)$ & 23 \\
\hline Oral and maxillofacial & $0(0.0)$ & $2(100.0)$ & 2 \\
\hline Otolaryngology & $10(40.0)$ & $15(60.0)$ & 25 \\
\hline Paediatric surgery & $10(58.8)$ & $7(41.2)$ & 17 \\
\hline Plastic surgery & $14(42.4)$ & $19(57.6)$ & 33 \\
\hline Trauma and orthopaedics & $38(52.1)$ & $35(47.9)$ & 73 \\
\hline Urology & $14(45.2)$ & $17(54.8)$ & 31 \\
\hline Vascular surgery & $29(70.7)$ & $12(29.3)$ & 41 \\
\hline \multicolumn{4}{|l|}{ Grade } \\
\hline Foundation year trainee & $5(38.5)$ & $8(61.5)$ & 13 \\
\hline Core surgical trainee & $41(34.4)$ & $78(65.6)$ & 119 \\
\hline StR 3-4/SpR 1-2 & $70(55.6)$ & $56(44.4)$ & 126 \\
\hline StR 5-6/SpR 3-4 & $49(48.5)$ & $52(51.5)$ & 101 \\
\hline StR 7-8/SpR 5-6 & $23(20.7)$ & $54(48.6)$ & 111 \\
\hline Clinical Fellow & $5(55.6)$ & $4(44.4)$ & 9 \\
\hline Research Fellow & $24(64.9)$ & $13(35.1)$ & 37 \\
\hline Other training grade & $9(64.3)$ & $5(35.7)$ & 14 \\
\hline Post-CCT non-consultant grade & $12(63.2)$ & $7(36.8)$ & 19 \\
\hline
\end{tabular}

In the UK, Specialty Registrar grade numbering continues on from core training and is replacing the old Specialist Registrar grade

$C C T$ Certificate of Completion of Training, $S p R$ specialty registrar, StR specialist registrar

'Other' mentors were most commonly a consultant for whom they had worked previously, an educational supervisor or an academic supervisor. Of the mentors, $90.2 \%$ were in the same specialty as the mentee, $60.7 \%$ were at the same hospital and $88.7 \%$ were in the same training region.

The modal duration of the mentoring relationship was 1-2 years $(24.4 \%)$, although there was a distribution between 1-3 months and 7 years (Fig. 1b). There was a wide variation in frequency of mentoring sessions (Fig. 1c). Mentoring was most commonly face to face $(89.1 \%)$; email and telephone were also popular media for a mentoring relationship (Fig. 1d). Mentoring was performed informally without any documentation by $64.7 \%$, formally with documentation by $3.3 \%$, whilst $32 \%$ used a combination of both methods. Most mentors provide mentoring related to clinical and professional matters (99.3\%) versus pastoral and non-clinical matters $(41.1 \%)$. Figure 2 demonstrates how trainees perceived mentoring had influenced their personal and professional lives, with career progression being influenced most positively. Of the trainees, $42.9 \%$ rated the usefulness of mentoring as strongly positive, whilst $52.7 \%$ rated it as positive, $4.0 \%$ neutral and $0.4 \%$ strongly negative.

Only 28 trainees $(10.2 \%)$ with a mentor experienced problems with their current mentoring; the key themes identified are detailed in Table 2.

Of the $51.3 \%$ of trainees without a mentor, $89.7 \%$ would like a clinical mentor and $51.0 \%$ would like a pastoral mentor. There was no significant difference with regard to gender or grade of trainee. Of those without a mentor, $73.8 \%$ felt that having a mentor during surgical training was 'very important', $23.4 \%$ felt that it was 'slightly important' and only $2.8 \%$ thought that it 'didn't matter'.

The ideal mentoring programme

Priorities for areas of mentoring included career progression $(94.9 \%)$, research $(75.2 \%)$, clinical skills $(66.9 \%)$ and clinical confidence (58.4\%) (Fig. 3). According to respondents, the ideal mentor is one who maintains confidentiality, works in the same region and specialty as the mentee, is chosen by the mentee and has received mentoring training (Fig. 4). Other desirable attributes for a mentor that were frequently cited included approachability, interest in the trainee and the ability to find time for them.

Ideally, trainees would prefer face-to-face mentoring (94.7\%), although email $(50.6 \%)$ and telephone $(30.6 \%)$ were also acceptable media. SMS mobile phone messaging (14.7\%) and audio/teleconference facilities such as Skype (10.4\%) were less popular options. A total of $74.5 \%$ wanted informal undocumented mentoring sessions, whilst only $9.6 \%$ wanted formal, documented mentoring; $21.8 \%$ had no preference. Of the trainees, $85.8 \%$ felt that the ideal mentor would be a consultant, $14.0 \%$ a registrar and 


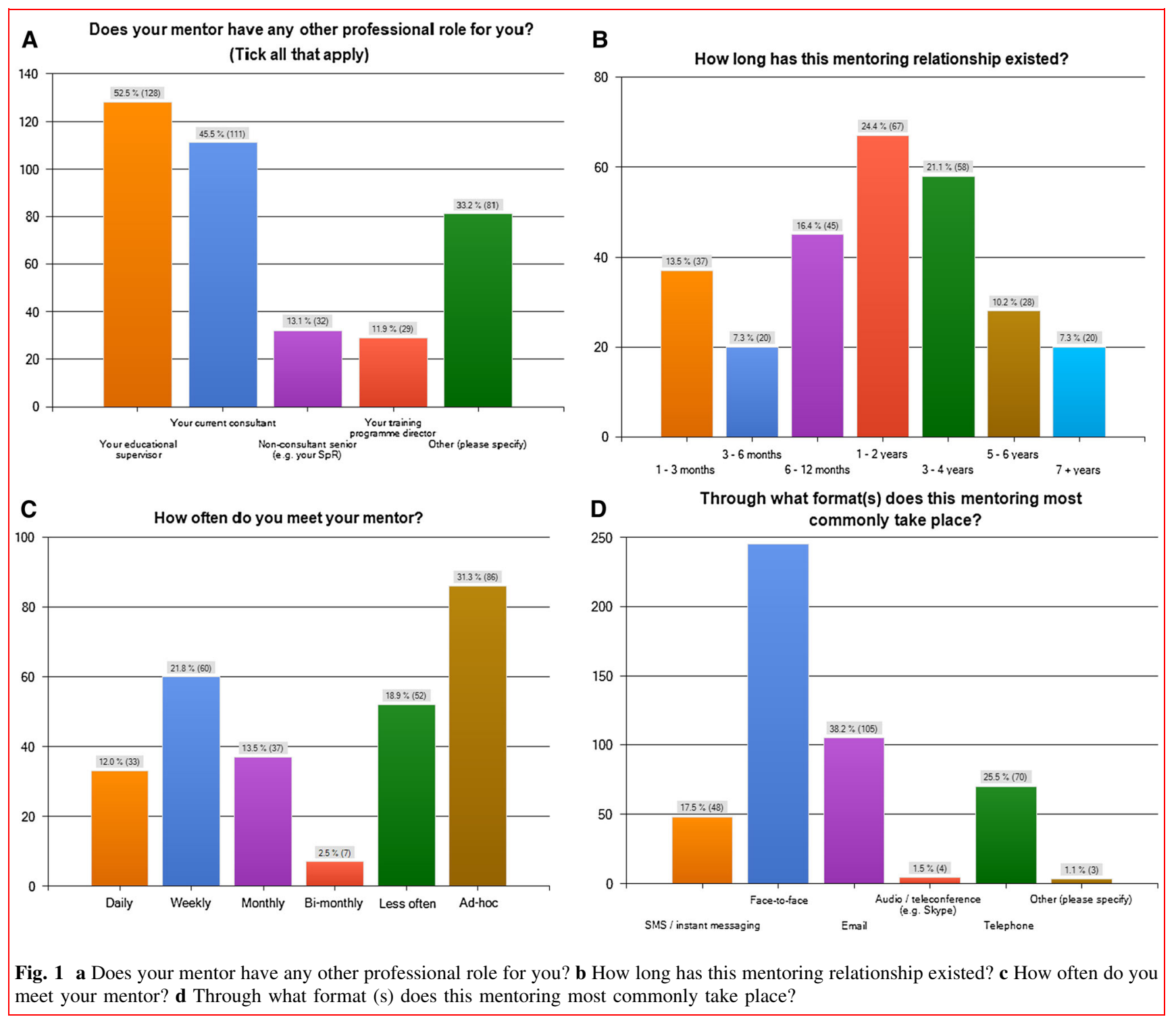

$0.2 \%$ a core trainee. No trainee chose an ideal mentor who was at a stage of training more junior than his or her own. Of the 81 trainees who chose a registrar as their ideal mentor, $21 \%$ were foundation trainees, $49 \%$ were CT1 or CT2, $5 \%$ were CT3, $16 \%$ registrars and $9 \%$ were other grades. Only 13 registrars stated that their ideal mentor would be another registrar.

\section{Acting as a mentor}

A total of $46.9 \%$ of respondents had acted as a mentor, whilst $94.3 \%$ of surgical trainees would be willing to act as a mentor whilst still a trainee. There is a wide variation in how often mentors were willing or able to meet their mentees: monthly sessions were most frequently reported $(36.4 \%)$, then ad hoc sessions (21.4\%), bi-monthly $(17.8 \%)$, weekly $(9.8 \%)$, less often $(6.2 \%)$ and daily
$(0.9 \%) ; 7.5 \%$ had no preference. Most mentors also wanted to meet face to face $(66.8 \%)$. Respondents would prefer to mentor core trainees $(75.4 \%)$, foundation trainees $(71.9 \%)$ or medical students $(55.0 \%)$. Only $22.1 \%$ were willing to mentor registrars, and $85 \%$ of these were current registrars or post-CCT, with willingness increasing with seniority. As a mentor, trainees wanted to offer informal, undocumented mentoring $(50.3 \%)$ over formal mentoring $(6.9 \%)$. Only $8.7 \%$ had received formal mentoring training; $83 \%$ of trainees would like some form of mentoring and coaching training.

\section{Discussion}

This is the first study of UK and Irish surgical trainees to investigate the current status and perceptions of mentoring 
Fig. 2 How has the mentoring you have received influenced you personally and professionally?
How has the mentoring you have received influenced you personally and professionally?

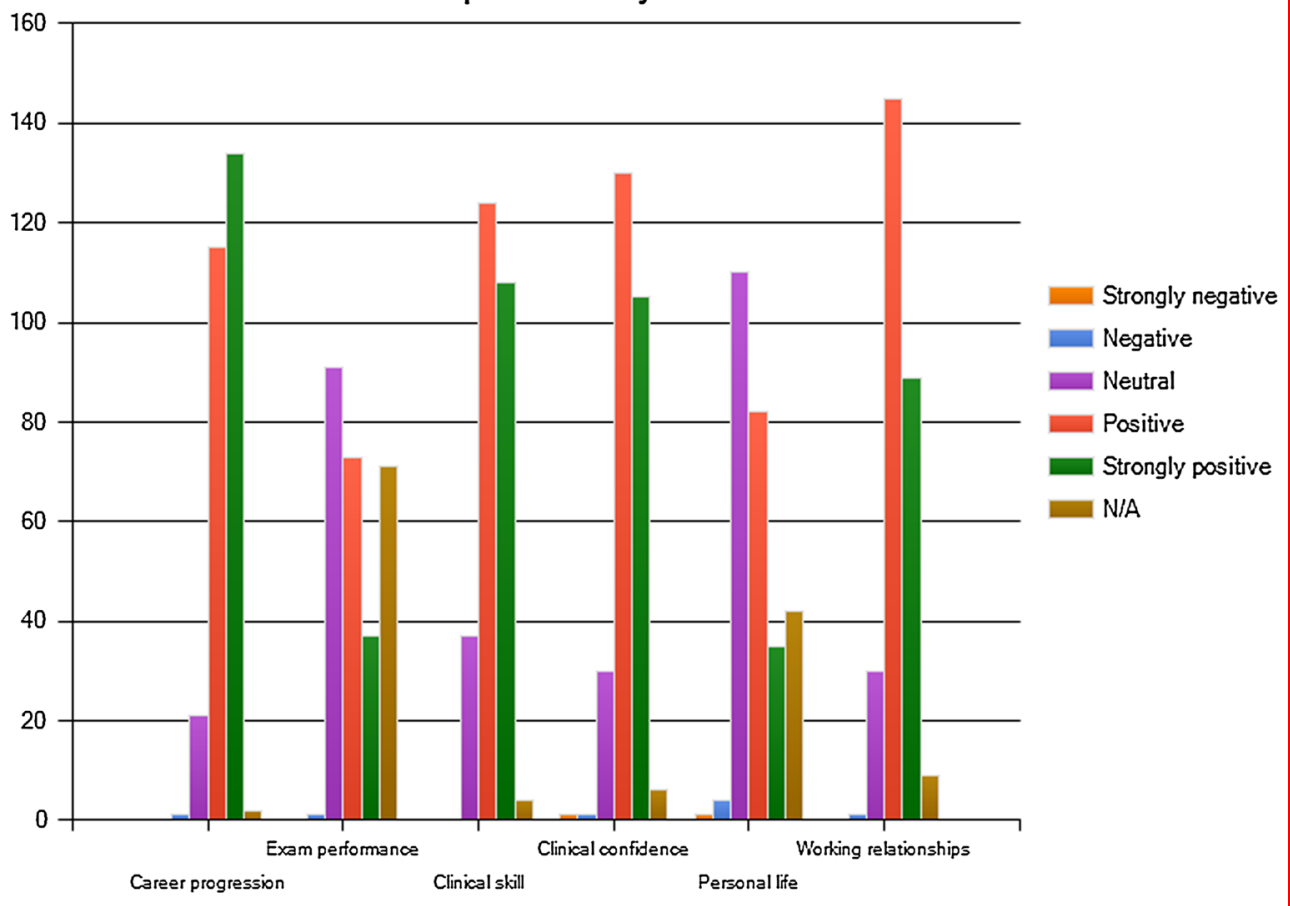

Table 2 Specific challenges highlighted by trainees pertaining to their current mentoring

Ad hoc nature of mentoring - it is dependent on who the trainee works for and whether they get on with their registrar or consultant

Currently informal and/or unstructured

Inaccessibility - both of mentoring and mentor (e.g. distance, changing training region, hospital)

Specialty of mentor can change as trainees rotate through posts

Training rotations also mean no continuity in mentorrelationship sometimes ends when rotation ends

Many mentors are not removed from the clinical setting

Difficult to maintain balanced relationship if mentor has concurrent role, e.g. clinical/educational supervisor

The 'critical' nature of surgeons can lead to constant critique, which can be undermining, regardless of how well meant or constructive it is

No set position of mentor either as identified person or role

in surgical training, together with the future needs for this. Approximately half reported that they did not currently have a mentor; $89.7 \%$ stated that they would like a mentor, with priorities for mentoring topics including career progression, research, clinical skills and clinical confidence. Only $8.7 \%$ of trainees currently acting as mentors had received formal mentoring training, whilst $83 \%$ wish to undertake this.

Surgical trainees in this study recognised the value of mentoring and its important role within surgery, with most rating its usefulness as 'strongly positive' or 'positive'. This is in keeping with the published literature to date; on this basis, it is likely that trainees would engage with a structured mentoring programme. Only $10.2 \%$ of trainees identified any problems with their current mentoring, and it is these areas that should be considered when designing any future formal mentoring program. It is notable that, despite providing respondents with an accepted definition of a mentor in our survey, some trainees wanted an 'experienced' mentor to 'advise', 'supervise' or 'teach them how to operate'. Mentoring schemes must make their own definition of mentoring, together with establishing clear aims and objectives at the outset in order to differentiate the mentoring relationship from additional clinical supervision and training.

Of the $48.7 \%$ who had a mentor, there was a trend towards trainees being more likely to self-identify a mentor as they increase in seniority. This may be explained by senior trainees being more likely to have chosen their specialty or sub-specialty interest and may be more motivated to find a mentor, or it may be that their longer period of training has given them time to identify someone suitably supportive. Notable regional variation was reported; in some regions, only one-third of trainees felt that they had a mentor compared with two-thirds in other regions. The results of this study are in keeping with those previously reported in a regional study of general surgery trainees [26], and emphasises the need to create nationally supported schemes that could replace variable regional practice. 
Fig. 3 Ideally, in which areas would you particularly like mentoring?

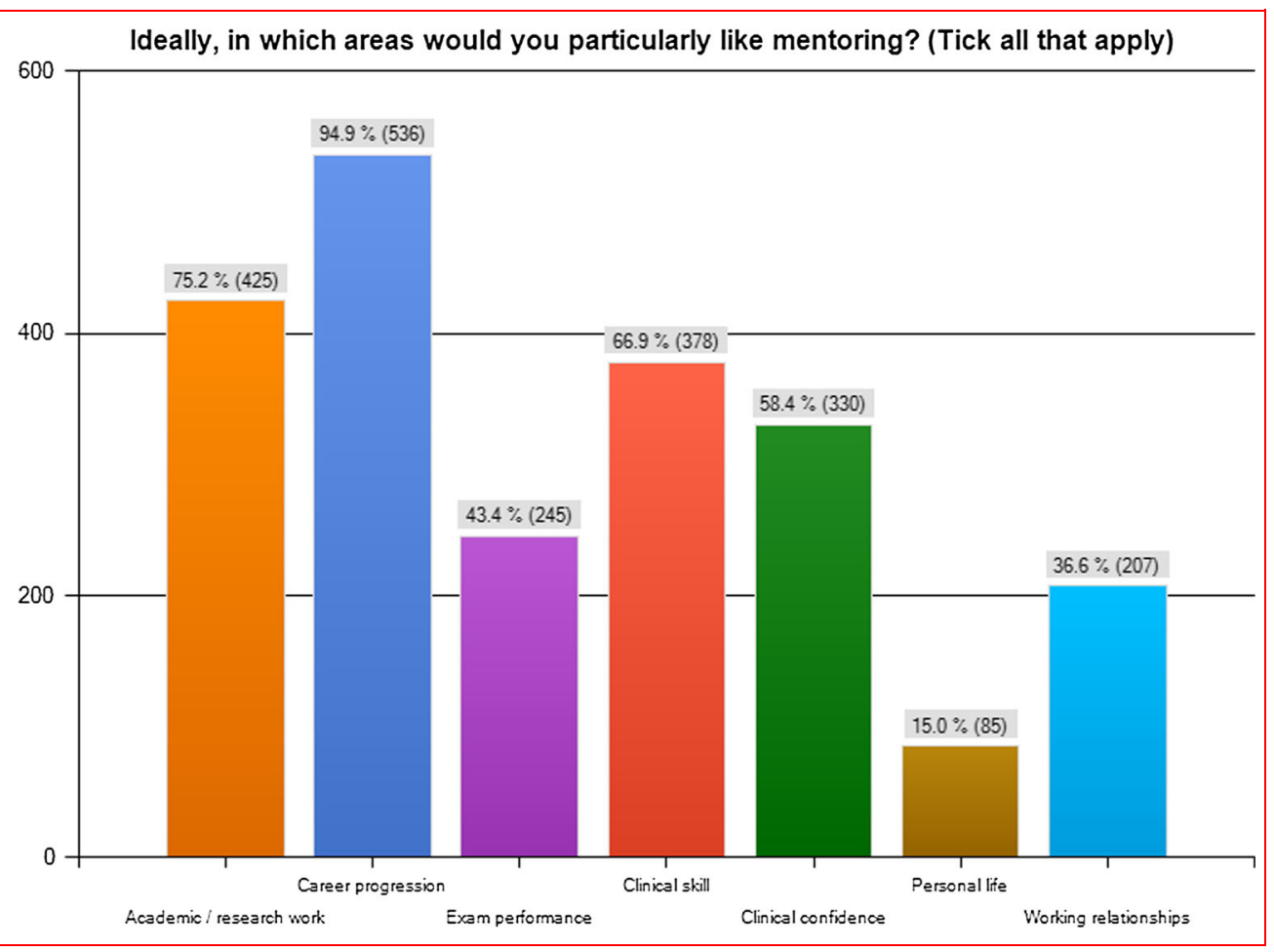

Fig. 4 How important to you are the following attributes of your ideal mentor?

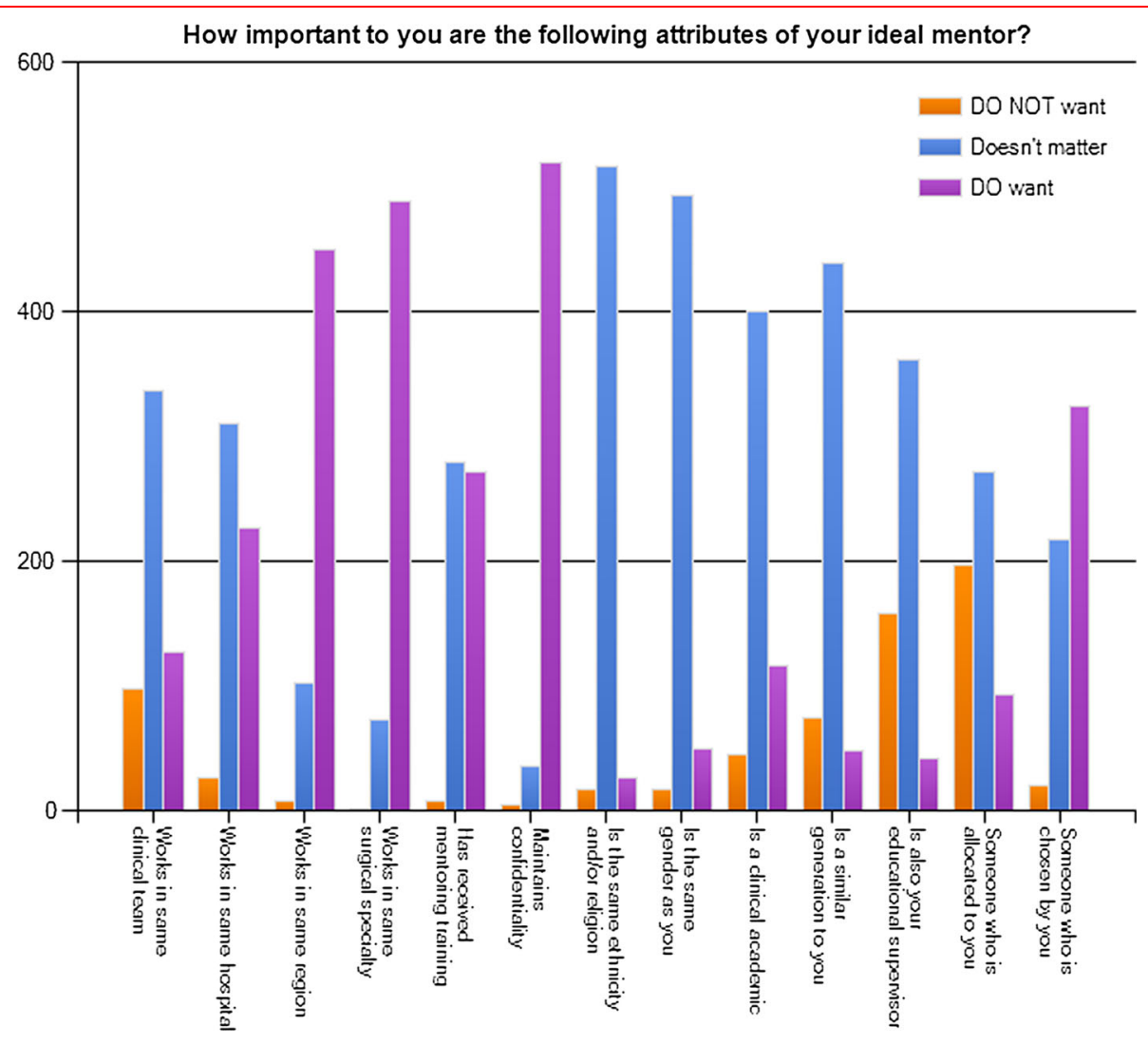

In this study, academic trainees were less likely to have a surgical mentor than were non-academic trainees. Mentorship is perceived as being important in this area, with numerous efforts described in the literature [27], although it has been acknowledged that the supporting evidence base for this could be stronger [8]. Nonetheless, academic 
Table 3 Summary of recommendations for future surgical mentoring schemes based on the findings of this study

The mentor should:

Be chosen by the trainee

Work in the same region and specialty as the mentee

Have received formal mentoring training

Maintain strict confidentiality

Be approachable

Take an interest in the trainee

Be accessible

Mentoring meetings should ideally be face to face

Mentoring meetings should be informal and undocumented if the trainee wishes

The ideal frequency of mentoring sessions is monthly, although flexibility is required

The system should be self-sustaining, with mentees wishing to mentor being offered training in mentoring schemes

trainees are a group that may particularly benefit from targeted mentoring, given the breaks in their clinical training for research activities while still being required to attain their clinical competencies in a similar timeframe. With regards to trainees undertaking less than full-time training (part-time) for non-research reasons, the proportions of trainees with a mentor was similar to the proportion in full-time training being mentored. However, extrapolations from both these groups are limited by the relatively small numbers of respondents, with $5.5 \%$ $(n=31)$ in less than full-time training and $9.4 \%(n=53)$ in academic clinical training.

Considering the trainees with a mentor, the majority identified a current or previous consultant, educational supervisor or academic supervisor as their mentor. It is apparent that some trainees and consultants are able to and do develop the trainee-trainer or supervisee-supervisor relationship into one of a mentee-mentor. However, it is unclear why some trainees and trainers take this step and how this progression occurs, including which of the parties drives the change. It also questions what thresholds or conditions trainees have for considering another surgeon as their mentor, with the definitions of what constitutes a mentoring relationship likely to differ. Traditionally, in healthcare, it has involved a more senior clinician taking someone more junior 'under their wing' and helping them with their professional development [9]. Some trainees may consider a reputed 'trainer' within their specialty and hospital to be a mentor in terms of surgical training. However, they may not feel able to approach them with matters outside the immediate clinical arena, including working with colleagues, pastoral issues, and life decisions such as moving regions or having a family. These issues clearly affect a trainee's ability to perform to their maximum potential.
The duration of the mentoring relationship and frequency of mentoring sessions varied widely. This variation is again likely to reflect the nature of the role adopted by the mentor and the trainee's definition of a mentor. A longstanding mentor may be paternalistic and an advisor (giving directive or prescriptive advice), rather than a mentor who coaches a trainee to reach their own goals. A coach in this sense would use specific non-directive techniques to achieve maximal potential in the coachee, with speedy, increased and sustainable effectiveness in their careers through focussed learning [28].

Half of trainees with a mentor met them less than every other month, with many trainees $(31.3 \%)$ having ad hoc sessions. This reflects the informal nature of mentoring currently adopted by UK trainees. In keeping with this, mentoring was performed informally without any documentation by $64.7 \%$ and formally with documentation by $3.3 \%$, whilst $32 \%$ used both methods. A number of newer mentoring schemes formalise mentoring with a specific number of sessions within a given period, although not all mandate formal documentation [29, 30].

Most mentors were within the same specialty, same hospital and same training region as the mentee. Although this may be convenient and help facilitate meetings, this may also give rise to additional concerns or limitations in the mentoring relationship. Guidance provided by one UK regional medical mentoring program states that the 'mentee should be discouraged from choosing a mentor on the basis of patronage, which may involve the mentee hoping that the mentor may give directive advice that may not be the best solution to this individual case or use their influence in promoting the interests of their mentee' [29]. Having a mentor in the same specialty, hospital or training region can foster this 'patronage' model; it can also make maintaining confidentiality with regard to sensitive issues difficult.

Mentees most frequently reported mentors as providing mentoring related to clinical and professional matters $(99.3 \%)$, as opposed to pastoral and non-clinical matters (41.1\%). This mentoring had a positive influence on their professional lives, with career progression being influenced most positively. Many trainees remained neutral about the effect of their current mentoring on their personal life and exam performance, which are areas that clinical mentors were less likely to focus on.

Whilst $60.4 \%$ of surgical trainees with a mentor felt that they had more than one mentor, over half did not have a mentor. Of those without a mentor, $73.8 \%$ felt that having a mentor during surgical training was 'very important' and only $2.8 \%$ thought that it 'didn't matter'. This again suggests that surgical trainees understand the value of mentoring within surgery, even if they do not have a mentor. However, amongst other relevant factors, it may 
be that some trainees do not recognise the potential advantages of receiving mentoring on a wide range of matters. It is arguably these trainees who could be the greatest beneficiaries of mentoring.

According to respondents, the ideal mentor is one who maintains confidentiality, works in the same region and specialty as the mentee, is chosen by the mentee, has had mentoring training, is approachable, has interest in the trainee and finds time for them. These aspects, although largely intuitive, need to be considered when establishing a new mentoring scheme and should be engendered in the mentors.

The method of communication that trainees felt would be ideal echoed what is currently being performed, with face-to-face mentoring $(94.7 \%)$ being most popular, followed by email (50.6\%) and telephone (30.6\%). A total of $74.5 \%$ wanted informal undocumented mentoring sessions, whilst only $9.6 \%$ wanted formal, documented mentoring. This could represent a false perception that formal mentoring involves documentation that will be passed on to training program coordinators and used as part of the annual training progression review process. It is important to emphasise when setting up a mentoring scheme that any documentation is kept confidential within the specifications of a confidentiality policy.

Most trainees felt that a consultant would be the ideal mentor, as opposed to a specialty or core trainee. Current perceptions of an ideal mentor appear to be based on seniority and the directive advice that they can give based purely on personal experiences. The idea of goal-orientated coaching is not widely practiced or well understood, yet this model can transcend the various hierarchies present in medicine. This model is based on the mentee taking responsibility for their own learning, with their goals forming the foundation of the mentoring sessions [31]. It uses a holistic model, encouraging active listening, building rapport, and questioning and challenging the mentee. The agenda can include anything from personal issues to career progression.

Overall, $46.9 \%$ of respondents had already acted as a mentor. Peer-mentoring and mentors having their own mentors are well established practices and can help mentors to maximise their mentoring potential [32]. A total of $94.3 \%$ of surgical trainees would be willing to act as a mentor whilst still a trainee. The modal potential frequency of meetings was one per month.

Respondents preferred to mentor core trainees, foundation trainees or medical students. Only $22.1 \%$ were willing to mentor registrars. This again reinforces the senioritybased view of mentoring, based on experience, expertise and advice. It is interesting that only 13 registrars felt that their ideal mentor would be another registrar, yet 93 registrars of varying grades were willing to mentor another registrar. No trainees wanted a junior mentor, yet five junior trainees were willing to mentor a more senior trainee. Mentors also wanted to offer informal, undocumented mentoring $(50.3 \%)$ over formal mentoring $(6.9 \%)$. This may reflect reluctance to document mentoring sessions or concerns over confidentiality.

Only $8.7 \%$ had received formal mentoring training, whilst $83 \%$ of trainees would like some form of mentoring and coaching training. There is currently little provision for this mentoring training within surgery other than isolated local projects in the UK and Ireland. Importantly, the scarcity of qualified mentors has previously been highlighted as a barrier in approximately half of studies investigating this area [13]. A lack of deliberate approach to mentoring in surgical training has been previously highlighted [33], and although limited guidance for mentors does exist [34, 35], this alone will not help develop mentoring frameworks and relationships without more formalised training opportunities. Likewise, the relationship will not achieve its potential benefits without mentees also being aware of how to initiate and cultivate this to their best advantage [36].

This study describes the experiences of a cross-sectional cohort of current surgical trainees. Although the large number of respondents may help provide a valid representation of current mentoring practice, all research of this nature is susceptible to responder bias. The wide distribution of the survey instrument and representation of all training grades, regions and specialties in the results helps mitigate against undue focus on any one subgroup. Nonetheless, there is the potential for these results to reflect those with either poor or excellent experiences of mentoring who may have been biased towards completing the survey. Furthermore, these results reflect current trainees within the UK and Republic of Ireland; the degree to which these findings can be extrapolated to the training programmes of other countries is unknown. Future research comparing mentoring experiences internationally, together with needs assessments for these, would help establish whether common themes exist for all surgical training programs. These will then need to be considered as new mentoring programs are deployed, together with an analysis of the long-term benefits and costs associated with these.

Recommendations for future mentoring schemes for surgical trainees

Based on these results, we believe that surgical trainees in all regions should have access to a mentor and be encouraged to develop a mentoring relationship. Developing a national mentoring scheme would facilitate this for 
both junior and senior trainees. When setting up such a mentoring scheme, the type of mentoring needs to be defined at the outset and mentee expectations must be addressed. Certain groups who would most benefit from mentoring, such as academic trainees, should be specifically targeted. Trainees may require more than one mentor, e.g. a clinical mentor, a pastoral mentor and an academic mentor. Based on the findings of this survey, we summarise recommendations for future surgical mentoring schemes in Table 3 .

\section{Conclusions}

This study suggests that less than half of surgical trainees are currently able to identify a mentor. The overwhelming majority of these trainees would like to be mentored on professional topics during their training and would additionally be willing to peer-mentor colleagues, although only a small minority have received training for this. Despite an identified need for formal mentoring training, there is currently no structure for organising this and little national provision for mentoring. This should be addressed to enable trainee surgeons to function at their maximum potential and overcome the numerous challenges faced in the modern training climate.

\section{References}

1. Chung DH (2012) Society of University Surgeons mentorship: fostering personal relationships. Surgery 152(3):304-308

2. Bulstrode C, Hunt V (2000) What is mentoring? Lancet 356(9244): 1788

3. Underhill CM (2006) The effectiveness of mentoring programs in corporate settings: a meta-analytical review of the literature. J Vocat Behav 68(2):292-307

4. Roch GR (1979) Much ado about mentors. Harv Bus Rev 57(1):14-20

5. Schapira MM, Kalet A, Schwartz MD, Gerrity MS (1992) Mentorship in general internal medicine: investment in our future. J Gen Int Med 7(2):248-251

6. Taherian K, Shekarchian M (2008) Mentoring for doctors. Do its benefits outweigh its disadvantages? Med Teach 30(4):e95-e99

7. Frei E, Stamm M, Buddeberg-Fischer B (2010) Mentoring programs for medical students-a review of the PubMed literature 2000-2008. BMC Med Educ 10:32

8. Sambunjak D, Straus SE, Marusic A (2006) Mentoring in academic medicine: a systematic review. JAMA 296(9):1103-1115

9. The Royal College of Surgeons of England (2004) Mentoring. A position statement by The Royal College of Surgeons of England. https://www.rcseng.ac.uk/publications/docs/mentoring.html. Accessed 7 Oct 2012

10. Moller MG, Karamichalis J, Chokshi N, Kaafarani H, Santry HP (2008) Mentoring the modern surgeon. Bull Am Coll Surg 93(7):19-25

11. Singletary SE (2005) Mentoring surgeons for the 21st century. Ann Surg Oncol 12(11):848-860
12. Miskovic D, Wyles SM, Ni M, Darzi AW, Hanna GB (2010) Systematic review on mentoring and simulation in laparoscopic colorectal surgery. Ann Surg 252(6):943-951

13. Entezami P, Franzblau LE, Chung KC (2012) Mentorship in surgical training: a systematic review. Hand 7(1):30-36

14. Burkhart RA, Tholey RM, Guinto D, Yeo CJ, Chojnacki KA (2014) Grit: a marker of residents at risk for attrition? Surgery 155(6):1014-1022

15. Cowan F, Flint S (2012) The importance of mentoring for junior doctors. BMJ Careers. http://careers.bmj.com/careers/advice/ view-article.html?id=20009962. Accessed 11 Dec 2012

16. Macafee DA (2008) Is there a role for mentoring in surgical specialty training? Med Teach 30(2):e55-e59

17. Sullivan MC, Bucholz EM, Yeo H, Roman SA, Bell RH, Sosa JA (2012) "Join the club": effect of resident and attending social interactions on overall satisfaction among 4390 general surgery residents. Arch Surg 147(5):408-414

18. Memon B, Memon MA (2010) Mentoring and surgical training: a time for reflection! Adv Health Sci Educ Theory Pract 15(5):749-754

19. Whittaker M, Cartwright A (2000) The mentoring manual. Gower, Aldershot

20. Fitzgerald JE, Giddings CE, Khera G, Marron CD (2012) Improving the future of surgical training and education: consensus recommendations from the Association of Surgeons in Training. Int J Surg 10(8):389-392

21. Joint Committee on Surgical Training (2014) http://www.jchst. org/. Accessed 4 Feb 2014

22. Woodward CA (1988) Questionnaire construction and question writing for research in medical education. Med Educ 22(4):345-363

23. Jones TL, Baxter MA, Khanduja V (2013) A quick guide to survey research. Ann R Coll Surg Engl 95(1):5-7

24. Eysenbach G (2004) Improving the quality of Web surveys: The Checklist for Reporting Results of Internet E-Surveys (CHERRIES). J Med Internet Res 6(3):e34

25. Bartlett JE, Kotrlik JW, Higgins CC (2001) Organizational research: determining appropriate sample size in survey research. Inf Technol Learn Perform J 19(1):43-50

26. Jaffer U, Pennell A, Musonda P (2010) General surgical trainee experiences of mentoring: a UK regional audit. J Surg Educ 67(1):19-24

27. Keyser DJ, Lakoski JM, Lara-Cinisomo S, Schultz DJ, Williams VL, Zellers DF, Pincus HA (2008) Advancing institutional efforts to support research mentorship: a conceptual framework and selfassessment tool. Acad Med 83(3):217-225

28. Brockbank A, McGill I (2006) Facilitating reflective learning through mentoring and coaching. Kogan Page, London

29. Viney R, Paice E (2010) The First Five Hundred. A Report on London Deanery's Coaching and Mentoring Service 2008-2010. London Deanery. http://mentoring.londondeanery.ac.uk/downloads/ files/London\%20Deanery\%20Coaching\%20and\%20Mentoring\%20\%20The\%20First\%20500.pdf. Accessed 14 Oct 2013

30. South West Peninsula Postgraduate Medical Education (2014) Peninsula Mentoring Programme-Resources for mentors. http:// www.peninsuladeanery.nhs.uk/index.php?option=com_content $\&$ view $=$ article $\& i d=1280 \&$ Itemid $=1184$. Accessed 13 Jan 2014

31. Driver M (2011) Coaching positively: lessons for coaches from positive psychology (Coaching in Practice). Open University Press, McGraw Hill Education, Maidenhead

32. Ghosh R, Reio TG Jr (2013) Career benefits associated with mentoring for mentors: a meta-analysis. $\mathrm{J}$ Vocat Behav 83(1):106-116

33. Healy NA, Glynn RW, Malone C, Cantillon P, Kerin MJ (2012) Surgical mentors and role models: prevalence, importance and associated traits. J Surg Educ 69(5):633-637 
34. Sanfey H, Hollands C, Gantt NL (2013) Strategies for building an effective mentoring relationship. Am J Surg 206(5):714-718

35. Ramani S, Gruppen L, Kachur EK (2006) Twelve tips for developing effective mentors. Med Teach 28(5):404-408
36. Zerzan JT, Hess R, Schur E, Phillips RS, Rigotti N (2009) Making the most of mentors: a guide for mentees. Acad Med 84(1):140-144 